\title{
Towards elimination of tuberculosis in a low income country: the experience of Cuba, 1962-97
}

\author{
Antonio Marrero, José A Caminero, Rodolfo Rodríguez, Nils E Billo
}

\begin{abstract}
Background-This study describes the epidemiological trends of tuberculosis in Cuba and the performance of the tuberculosis control programme. The circumstances that caused an increase in the incidence of new cases of tuberculosis between 1991 and 1994 had been analysed and were corrected in 1995-7.

Methods-A descriptive study of the incidence rates of new cases of tuberculosis notified from 1962 to 1997 was made, with special emphasis on the total change between 1965 and 1991 and the increase thereafter.
\end{abstract}

Results-The case notification rate of 14.7 per 100000 in 1994 was almost three times the rate found in 1991 (4.8 per 100000$)$ and reversed the mean annual decrease of $5 \%$ observed since 1965. This increase was almost twofold in the rate of smear positive new cases (4.4 per 100000 in 1991 and 8.3 in 1994). From 1971 onwards the programme had achieved a cure rate of $90 \%$ throughout the country with only $2 \%$ absconding by applying directly observed treatment. The main factors associated with the increasing trends were: (1) a probable underdetection of cases for the 1988-92 period that generated contagious sources in the community; (2) improved case finding from 1993 onwards and the introduction of an expanded case definition in 1994; (3) a considerable increase in the diagnostic delay from initial medical consultation to beginning of antituberculosis treatment (56.9 days in 1993); and (4) operational changes in the tuberculosis control programme due to the economic crisis in Cuba. In 1995, 1996 and 1997 it has been possible to reverse this trend, achieving rates of $14.1,13.5$, and 12.2 per 100000 , respectively $(7.6,7.6$, and 6.9 for smear positive cases) as a result of effective intervention correcting the problems identified. Reducing the diagnostic delay attributable to shortcomings in the health care system and the study of contacts were of particular importance for reestablishing the tuberculosis programme as a priority.

Conclusions-Cuba represents a good example of how it is possible to fight against tuberculosis effectively, even in a low income country, by applying control strategies advocated by the World Health Organisation and the International Union Against Tuberculosis and Lung Disease and by giving adequate support to the programme through political commitment.

(Thorax 2000;55:39-45)

Keywords: tuberculosis; elimination; low income country

Tuberculosis is probably the disease that has most extensively decimated the population throughout history ${ }^{1}$ and at present it is estimated that there are more patients with tuberculosis worldwide than ever before. ${ }^{2}$ Population growth, the pandemic with the human immunodeficiency virus, increased poverty, and other factors have been identified as contributing to an increase in tuberculosis in developing $^{3-6}$ and industrialised countries. ${ }^{7-12}$ This situation is unexpected because the scientific basis for the control of the disease has been established for several decades and the benefits that can be obtained from a well organised national tuberculosis programme have been extensively documented. ${ }^{13-15}$

The resurgence of tuberculosis cannot be attributed to the above factors. A major contributing factor is likely to be the nonimplementation of modern control measures or the dismantling of existing programmes ${ }^{76-18}$ as a result of the high costs of tuberculosis control. ${ }^{19}$ Analyses of cost effectiveness suggest, however, that treatment with short courses of chemotherapy is highly cost effective and is similar to oral rehydration therapy or measles vaccination. ${ }^{2023}$

In this context, the experience of a low income country such as Cuba, where the national tuberculosis programme has always enjoyed a high priority, might serve as a good example for the fight against tuberculosis. Of particular interest here is the period after 1989 with the economic depression and the subsequent increase in the number of new cases of tuberculosis.

The present study analyses the results obtained in the national tuberculosis programme in Cuba from 1962 to 1997. Special emphasis is given to the change in notification trends of tuberculosis between 1991 and 1994 and to the analysis and correction of identified weak points of the programme. Trends in tuberculosis are discussed with a focus on achieving elimination of tuberculosis (incidence rate of new smear positive cases less than 1 per 100000 population) ${ }^{10}$ by the year 2016 .

\section{Methods}

The study included all new cases of tuberculosis notified in the 169 municipalities of the 14 
provinces in Cuba between 1962 and 1997. In this country free health care services are provided to the whole population. The following Word Health Organisation definitions ${ }^{24}$ were used to define tuberculosis cases: (1) a case of pulmonary tuberculosis with positive sputum smear for acid fast bacilli, (2) a case of pulmonary tuberculosis with negative sputum smear (with positive or negative culture), and (3) a case of extrapulmonary tuberculosis. The case definition was expanded in 1994 to include cases with clinical symptoms and radiological features suggestive of tuberculosis but with negative sputum smears and negative culture. The detection of cases was based on passive case finding among patients seeking medical care with respiratory symptoms (cough and expectoration for more than 14 days) and active case finding by intensive screening of household contacts and high risk groups such as HIV infected individuals and other immunocompromised patients. All patients with a clinical suspicion of tuberculosis (respiratory symptoms) underwent two consecutive smear tests (three tests until 1993) with culture of the first sample. In patients with negative results a chest radiograph was required. Susceptibility testing to antituberculosis drugs was performed on all strains of $\mathrm{Myco}-$ bacterium tuberculosis isolated from sputum smear positive patients. The tests were done using the dilution and multiple proportion method. ${ }^{25}$ Sputum smear microscopy is performed in the national laboratory network in the 421 polyclinics and 87 hospital and institutional laboratories and by the 32 municipal and 14 provincial laboratories responsible for quality assurance and culture examinations. A national reference laboratory supervises and controls these activities.

Delay in the diagnosis of tuberculosis was assessed by a systematically applied questionnaire and was calculated for each patient as the interval between the onset of symptoms and initiation of antituberculosis treatment. The median time of delay was calculated for all patients in every year. The time elapsed from the onset of symptoms to medical consultation (patient's delay) and from the first medical consultation to the beginning of treatment (doctor's delay) was also calculated.

Antituberculosis treatment is provided free of charge to all new patients with tuberculosis and, since 1971, it is given on an outpatient basis. The intake of drugs is directly observed by a doctor or nurse. Therapeutic regimens have varied throughout the study period. In the beginning the regimen consisted of daily isoniazid and streptomycin during the first month followed by isoniazid and streptomycin twice a week for 11 months; after 1975 daily isoniazid, streptomycin, and ethambutol for two months followed by isoniazid and streptomycin twice a week for 10 months were used; in 1982 a regimen with daily isoniazid, rifampicin, streptomycin, and pyrazinamide for two months followed by isoniazid and streptomycin twice a week for seven months was introduced; and from 1986 to the present time daily isoniazid, rifampicin, pyrazinamide, and ethambutol for two months followed by isoniazid and rifampicin twice a week for five months is the recommended regimen.

Since 1965 patients with tuberculosis have been given sick leave from work and they receive a full salary during the entire treatment period. Patients have the assurance that their position will be retained during treatment and that they will be re-employed in their previous job after completion of antituberculosis therapy. ${ }^{26}$

Since 1994 the outcome of treatment has been systematically evaluated for each one year cohort of patients and defined as follows: cured $=$ patient with negative sputum smears at the fourth and seventh month of therapy; treatment completed $=$ patient who completed treatment but for whom no microbiological studies were available prior to completion of treatment; defaulted $=$ patients who failed to take their medication for more than two months; treatment failure $=$ patients with smear positive results at the fourth month of treatment; died $=$ patients who died during the period of treatment and were included in the category of deaths regardless of cause of death; transferred out $=$ patients who were diagnosed and initiated treatment in one centre and were subsequently referred to complete antituberculosis therapy in another centre and for whom treatment results are unknown.

The contacts of every patient with tuberculosis, both smear positive and smear negative, were systematically investigated. Assessment of contacts of tuberculosis cases included clinical evaluation, chest radiography, and tuberculin

Table 1 Total number of new tuberculosis cases, notification rate per 100000 inhabitants, and distribution of smear positive cases in Cuba, 1962-97

\begin{tabular}{|c|c|c|c|c|}
\hline Year & $\begin{array}{l}\text { Total new } \\
\text { cases }\end{array}$ & Rate & $\begin{array}{l}\text { Smear positive } \\
(\%)^{\star}\end{array}$ & Rate \\
\hline 1962 & 2818 & 38.8 & $2516(89.3)$ & 34.6 \\
\hline 1963 & 2768 & 36.2 & $2472(89.3)$ & 32.3 \\
\hline 1964 & 3909 & 52.6 & $3491(89.3)$ & 47.0 \\
\hline 1965 & 4958 & 65 & $4427(89.3)$ & 58.0 \\
\hline 1966 & 2846 & 36.5 & $2541(89.2)$ & 32.6 \\
\hline 1967 & 2950 & 37.2 & $2634(89.2)$ & 33.2 \\
\hline 1968 & 3310 & 41 & $2956(89.3)$ & 36.6 \\
\hline 1969 & 3607 & 43.9 & $3221(89.2)$ & 39.2 \\
\hline 1970 & 2606 & 31.2 & $2327(89.2)$ & 27.9 \\
\hline 1971 & 1543 & 17.8 & $1378(89.3)$ & 15.9 \\
\hline 1972 & 1272 & 14.5 & $1136(89.3)$ & 12.9 \\
\hline 1973 & 1396 & 15.7 & $1247(89.3)$ & 14.0 \\
\hline 1974 & 1418 & 15.6 & $1266(89.2)$ & 13.9 \\
\hline 1975 & 1326 & 14.3 & $1184(89.2)$ & 12.8 \\
\hline 1976 & 1270 & 13.4 & $1134(89.2)$ & 12.0 \\
\hline 1977 & 1257 & 13.1 & $1123(89.4)$ & 11.7 \\
\hline 1978 & 1261 & 13 & $1154(91.5)$ & 11.8 \\
\hline 1979 & 1133 & 11.6 & $1044(92.1)$ & 10.7 \\
\hline 1980 & 1133 & 11.6 & $1004(88.6)$ & 10.3 \\
\hline 1981 & 833 & 8.5 & $743(89.2)$ & 7.6 \\
\hline 1982 & 815 & 8.3 & $711(87.2)$ & 7.2 \\
\hline 1983 & 762 & 7.7 & 685 (89.9) & 6.9 \\
\hline 1984 & 705 & 7.1 & $638(90.5)$ & 6.3 \\
\hline 1985 & 680 & 6.8 & 603 (88.9) & 5.9 \\
\hline 1986 & 656 & 6.4 & $561(85.5)$ & 5.5 \\
\hline 1987 & 630 & 6.2 & $550(87.3)$ & 5.3 \\
\hline 1988 & 628 & 5.9 & $551(87.7)$ & 5.2 \\
\hline 1989 & 581 & 5.5 & $514(88.5)$ & 4.8 \\
\hline 1990 & 546 & 5.1 & $491(89.9)$ & 4.6 \\
\hline 1991 & 514 & 4.8 & $466(90.6)$ & 4.4 \\
\hline 1992 & 633 & 5.8 & $591(93.3)$ & 5.5 \\
\hline 1993 & 789 & 7.2 & $718(91)$ & 6.6 \\
\hline 1994 & 1617 & 14.7 & 914 (56.5) & 8.3 \\
\hline 1995 & 1553 & 14.1 & $834(53.7)$ & 7.6 \\
\hline 1996 & 1486 & 13.5 & $835(56.2)$ & 7.6 \\
\hline 1997 & 1346 & 12.2 & $765(56.8)$ & 6.9 \\
\hline
\end{tabular}

^Percentage of sputum smear positive cases out of all cases. 


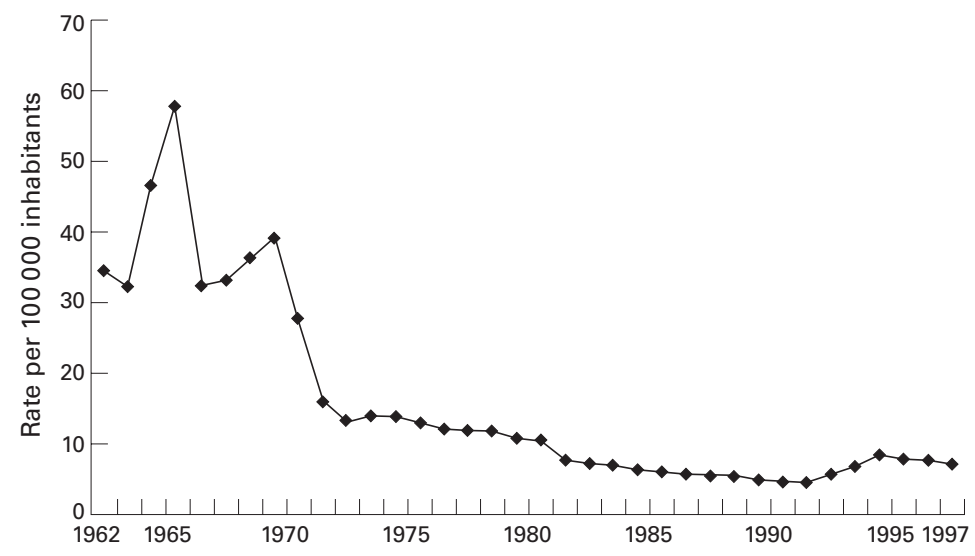

Figure 1 Epidemiological trends of tuberculosis in Cuba, 1962-97.

skin testing in subjects under 15 years of age. Tuberculin positive subjects with subclinical tuberculous infection are treated prophylactically with isoniazid whereas non-BCG vaccinated tuberculin negative children receive prophylactic chemotherapy and BCG vaccine. In contacts over the age of 15 years only active detection of respiratory symptoms is done, but neither tuberculin skin testing nor preventive therapy is used. Finally, all newborn infants are given BCG vaccination at birth and, until 1993, children were revaccinated in the fifth grade of school. Since 1987 commercial diagnostic kits have been used for the detection of HIV antibodies and positive results are confirmed by Western blot analysis in every patient with tuberculosis

STATISTICAL ANALYSIS

Data and operational indicators of the programme were obtained from the National Tuberculosis Register (instituted in 1964) that establishes the statutory notification of tuberculosis patients. Epi Info, version 6.04 and Epi Map, version 2 statistical software packages (US Centers for Disease Control and Prevention) were used for data analysis. A descriptive analysis of the following parameters was made: (1) distribution of case notification rates by year, age and sex (annually updated according to the population census); (2) number of cases with cough and/or expectoration for more than

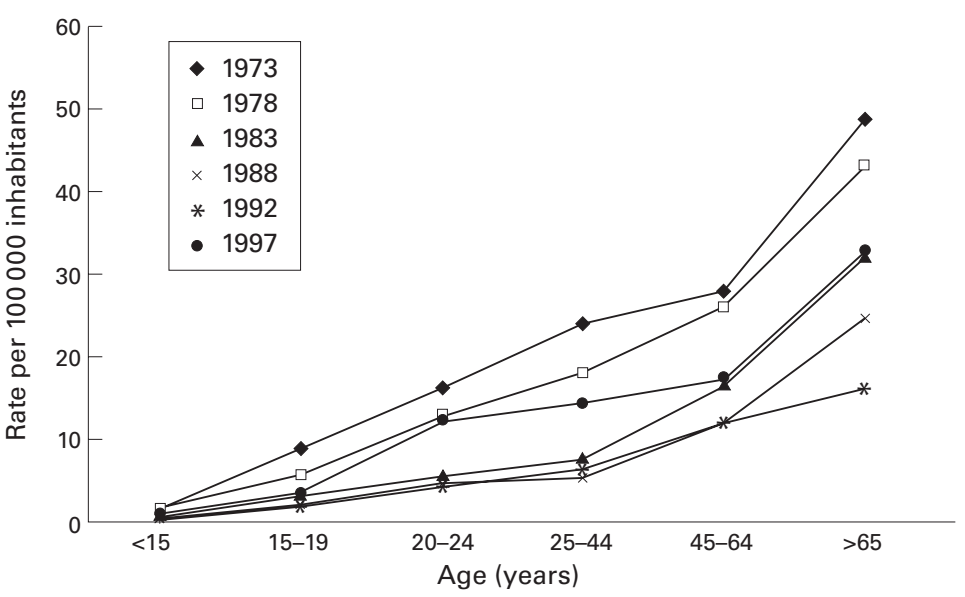

Figure 2 Incidence of new cases of tuberculosis by age per 100000 inhabitants in Cuba in 1973, 1978, 1983, 1988, 1992, 1997. Source: National Tuberculosis Register.
14 days studied every year (among the total number of general consultations); (3) percentage of cases with respiratory symptoms for more than 14 days in whom a first and second sputum smear examination was performed; (4) diagnostic delay (in days) among cases with respiratory symptoms for more than 14 days; (5) percentage of sputum smear positive cases out of all cases; (6) treatment outcome in the cohort of smear positive patients enrolled in the national tuberculosis programme in the previous year, calculating the proportion of cases with the six possible outcomes; (7) mean number of contacts studied for each patient and total number and percentage of tuberculosis cases found among the contacts; and (8) percentage of children who received BCG vaccination at birth.

\section{Results}

Table 1 shows the numbers and rates of new tuberculosis cases (with the percentage of new smear positive cases) in Cuba from 1962 to 1997 and fig 1 shows the epidemiological trends of tuberculosis during this period. The highest notification rate since the institution of the national tuberculosis programme was recorded in 1965 with 4958 cases (rate of 65 per 100000 population). This was followed by a decreasing trend (average annual decrease of 5\%) until 1991 when 514 cases were notified (rate of 4.8 per 100000 ). However, notification rates of tuberculosis showed an average annual increase of $49.7 \%$ between 1991 and 1994 (rate of 14.7 per 100000 in 1994). The rate in 1994, using a new expanded case definition, was very close to that in 1972 but the rate of smear positive cases was close to that of the years 1980-1. This trend changed in 1995, 1996, and 1997 with reported notification rates of $14.1,13.5$, and 12.2 per 100000 , respectively, showing a decrease of $4.1 \%$ from 1994 to $1995,4.3 \%$ from 1995 to 1996 , and $9.6 \%$ from 1996 to 1997 (fig 1). In the period between 1994 and 1996 there was a more marked increase in the total number of notified cases than in new smear positive cases due to a change in the case definition and, for this reason, the proportion of new smear positive cases decreased (table 1). In 1994 cases with suggestive clinical symptoms and radiological features but negative sputum smear cultures were included in the new case definition. However, there was also an important increase in notification of new smear positive cases between 1991 and 1994 (average annual increase of $23.6 \%$ ), with a decrease of $8.5 \%$ from 1994

Table 2 Cohort analysis of treatment results, Cuba, 1994-6

\begin{tabular}{llll}
\hline & 1994 & 1995 & 1996 \\
\hline Smear positive & 914 & 834 & 835 \\
Evaluated & $870(95.2)$ & $824(98.8)$ & $830(99.4)$ \\
Cured & $815(93.7)$ & $775(94.1)$ & $765(92.2)$ \\
Defaulted & $16(1.8)$ & $13(1.6)$ & $8(1)$ \\
Died & $38(4.4)$ & $37(4.5)$ & $45(5.4)$ \\
Failures & $8(0.9)$ & $7(0.8)$ & $10(1.2)$ \\
Transferred out & $9(1)$ & $6(0.7)$ & $2(0.2)$ \\
\hline
\end{tabular}

Values in parentheses are percentages.

*Includes patients who completed treatment and for whom no bacteriological studies were available at the end of treatment. 
Table 3 Numbers of smears performed in patients with respiratory symptoms (cough and/or expectoration for more than 14 days), Cuba, 1972-96

\begin{tabular}{|c|c|c|c|c|c|}
\hline \multirow[b]{2}{*}{ Year } & \multirow{2}{*}{$\begin{array}{l}\text { No. with } \\
\text { respiratory } \\
\text { symptoms }\end{array}$} & \multicolumn{2}{|l|}{ Smear test } & \multicolumn{2}{|l|}{ Smear test } \\
\hline & & First & $\%$ & Second & $\%$ \\
\hline 1972 & 38365 & 37598 & 98.0 & & \\
\hline 1973 & 47063 & 45651 & 97.0 & & \\
\hline 1974 & 49867 & 47872 & 96.0 & & \\
\hline 1975 & 46298 & 44446 & 96.0 & & \\
\hline 1976 & 63849 & 48525 & 76.0 & & \\
\hline 1977 & 63488 & 58092 & 91.5 & & \\
\hline 1978 & 62885 & 53075 & 84.4 & & \\
\hline 1979 & 60501 & 47735 & 78.9 & & \\
\hline 1980 & 67230 & 51431 & 76.5 & & \\
\hline 1981 & 70741 & 56027 & 79.2 & & \\
\hline 1982 & 69288 & 57855 & 83.5 & & \\
\hline 1983 & 74929 & 64439 & 86.0 & & \\
\hline 1984 & 79789 & 70135 & 87.9 & & \\
\hline 1985 & 83736 & 75446 & 90.1 & & \\
\hline 1986 & 86515 & 78729 & 91.0 & & \\
\hline 1987 & 86996 & 78296 & 90.0 & & \\
\hline 1988 & 69507 & 62000 & 89.2 & & \\
\hline 1989 & 59658 & 52499 & 88.0 & & \\
\hline 1990 & 50716 & 43311 & 85.4 & & \\
\hline 1991 & 50680 & 40291 & 79.5 & & \\
\hline 1992 & 49923 & 43700 & 87.5 & & \\
\hline 1993 & 62370 & 44348 & 71.1 & & \\
\hline 1994 & 91695 & 69239 & 75.5 & 51866 & 56.6 \\
\hline 1995 & 139840 & 109967 & 78.6 & 80697 & 57.7 \\
\hline 1996 & 167790 & 140427 & 83.7 & 103764 & 61.8 \\
\hline 1997 & 179493 & 155028 & 86.3 & 132478 & 73.8 \\
\hline
\end{tabular}

Table 4 Delay (in days) in the diagnosis of tuberculosis, Cuba, 1993-7

\begin{tabular}{llll}
\hline Year & Interval 1 & Interval 2 & Total \\
\hline 1993 & 38.1 & 56.9 & 95 \\
1994 & 27.2 & 46.8 & 74 \\
1995 & 19.8 & 31.4 & 51.2 \\
1996 & 18.9 & 20.1 & 39 \\
1997 & 19.7 & 14.2 & 33.9 \\
\hline
\end{tabular}

Interval $1=$ from onset of symptoms to consultation (patient's delay).

Interval 2 = from initial consultation to treatment (doctor's delay).

Total $=$ from onset of symptoms to treatment (total delay).

to 1995 (the rate of 1996) and of $9.2 \%$ from 1996 to 1997. The distribution of new cases of tuberculosis by age in rates per 100000 from 1973 to 1997 are shown in fig 2.

Since the introduction of systematic evaluation of treatment outcome in 1994, the proportion of patients with smear positive tuberculosis who were declared cured has been over $92 \%$, with defaulters accounting for less than $2 \%$ and failures for only $1.2 \%$ in 1996 (table 2). The percentage of deaths was $5.4 \%$ in 1996, most of them in elderly patients (36 cases).

Information about patients with respiratory symptoms (cough and/or expectoration for more than 14 days) detected in the national tuberculosis programme is detailed in table 3 . There was a clear decrease in the number of patients identified with respiratory symptoms lasting for more than 14 days during the period 1989-92 and a marked increase from 1994 onwards. There was also a decrease in the number of smear examinations carried out during the period 1991-3. The delays in diagnosis, both in relation to the patient and to the health care system, are shown in table 4 . It should be noted that the diagnostic delay attributable to the health care system (from initial consultation to treatment) was 56.9 days
Table 5 Study of contacts of tuberculosis cases, Cuba, 1972-96

\begin{tabular}{|c|c|c|c|c|}
\hline Year & Contacts & $\begin{array}{l}\text { Mean no. of } \\
\text { contacts per } \\
\text { patient }\end{array}$ & TB cases * & $\% t$ \\
\hline 1972 & 4581 & 3.6 & 17 & 0.4 \\
\hline 1973 & 5704 & 4.1 & 24 & 0.4 \\
\hline 1974 & 6978 & 4.9 & 13 & 0.2 \\
\hline 1975 & 6943 & 5.2 & 23 & 0.3 \\
\hline 1976 & 4676 & 3.7 & 5 & 0.1 \\
\hline 1977 & 5907 & 4.7 & 58 & 1.0 \\
\hline 1978 & 5853 & 4.6 & 17 & 0.3 \\
\hline 1979 & 5108 & 4.5 & 7 & 0.1 \\
\hline 1980 & 4721 & 4.2 & 14 & 0.3 \\
\hline 1981 & 3459 & 4.2 & 6 & 0.2 \\
\hline 1982 & 3365 & 4.1 & 3 & 0.1 \\
\hline 1983 & 3420 & 4.5 & 3 & 0.1 \\
\hline 1984 & 2978 & 4.2 & 7 & 0.2 \\
\hline 1985 & 2504 & 3.7 & 3 & 0.1 \\
\hline 1986 & 2431 & 3.7 & 3 & 0.1 \\
\hline 1987 & 2473 & 3.9 & 1 & 0.0 \\
\hline 1988 & 2325 & 3.7 & 1 & 0.0 \\
\hline 1989 & 2696 & 4.6 & 3 & 0.1 \\
\hline 1990 & 1788 & 3.3 & 1 & 0.1 \\
\hline 1991 & 1801 & 3.5 & 1 & 0.1 \\
\hline 1992 & 1852 & 2.9 & 4 & 0.2 \\
\hline 1993 & 3784 & 4.8 & 6 & 0.2 \\
\hline 1994 & 8022 & 5.0 & 8 & 0.1 \\
\hline 1995 & 12845 & 8.3 & 10 & 0.1 \\
\hline 1996 & 9839 & 6.6 & 33 & 0.3 \\
\hline 1997 & 16826 & 12.5 & 18 & 0.1 \\
\hline
\end{tabular}

Source: National Tuberculosis Register System.

*Total number of tuberculosis cases found among the contacts. †Percentage of contacts who were found to have tuberculosis.

Table 6 Distribution of initial resistance to antituberculous agents in 834 smear positive cases of tuberculosis, Cuba, 1995

\begin{tabular}{lcl}
\hline Drug & No. of cases & $\%$ \\
\hline Isoniazid & 2 & 0.24 \\
Rifampicin & 1 & 0.12 \\
Streptomycin & 38 & 4.55 \\
Isoniazid/rifampicin & 1 & 0.12 \\
Streptomycin/rifampicin & 2 & 0.24 \\
Isoniazid/streptomycin & 8 & 0.95 \\
Isoniazid/streptomycin/rifampicin & 2 & 0.24 \\
Total & 54 & 6.5 \\
\hline
\end{tabular}

Source: National Reference Laboratory.

in 1993, but this figure has been reduced to 14.2 days in 1997.

The mean number of contacts examined for each case of tuberculosis decreased from 4.6 in 1989 to 2.9 in 1992 . This was followed by a marked increase of 8.3 in 1995 and 12.5 in 1997 (table 5).

The percentage of BCG vaccinated infants throughout the study period has been close to $100 \%$ since 1978 (98.5\% in 1997). The last case of tuberculous meningitis in children under five years of age in Cuba occurred in 1974.

The first case of the acquired immunodeficiency syndrome (AIDS) was registered in 1986. As of 31 December 1997, a total of 676 cumulative cases has been notified (rate 6.1 per 1000000 ) and $77 \%$ of these patients have died. HIV infection is almost exclusively sexually transmitted (97.7\%), 50.7\% among homo/ bisexual men and $47 \%$ due to heterosexual transmission. The first case of tuberculosis in HIV infected individuals was detected in 1992, with a total of 126 cases up to the end of 1997 (29 cases in 1997).

The rate of initial resistance to antituberculosis drugs is very low, especially for isoniazid and rifampicin. In $19951.55 \%$ of the cases showed initial resistance to isoniazid and $0.7 \%$ 
to rifampicin (table 6). The highest initial resistance was to streptomycin, a drug widely used in Cuba in the past. ${ }^{26}$

\section{Discussion}

The implementation of the national tuberculosis programme started in Cuba in 1959 when official registers were established and the programme was integrated into the primary health care system. ${ }^{26}{ }^{27}$ Directly observed treatment in outpatient clinics was introduced in 1971 and rifampicin was included in chemotherapy regimens in $1982 .{ }^{26-29}$ These changes resulted in an average annual decrease in new cases of tuberculosis of 5\% from 1965 to $1991 .^{29}{ }^{30}$ The case notification rate of 4.8 per 100000 achieved in 1991, together with the low rate of tuberculosis infection among Cuban refugees on entering the $\mathrm{USA}^{31-33}$ and the low prevalence of bovine tuberculosis, ${ }^{34}$ show that Cuba is in one of the best epidemiological positions of the world, including most industrialised countries, ${ }^{7-12} 173536$ and seems to indicate the possibility of rapid elimination of the disease. ${ }^{30}$

However, as has occurred in many other countries in the past decade, ${ }^{3-12}$ there has been a significant increase in new cases of tuberculosis in Cuba, ${ }^{37}$ almost threefold from 1991 to 1994 for all cases and twofold for smear positive cases. ${ }^{38}$ The notification rate of total cases of tuberculosis in 1994 was close to that of 1972, whereas the rate of new smear positive cases was close to that of 1980-1. The difference in the increase may be due to the change in case definition adopted in 1994. This increase occurred despite the fact that Cuba achieved the two WHO targets established in 1991 for the year $2000^{39}$ - that is, a detection rate of smear positive cases of $70 \%$ and a cure ratio of $85 \%$ - objectives that are still far from being achieved in most parts of the world. ${ }^{16}$ For more than 20 years Cuba had a programme which guaranteed a high proportion of cured cases thanks to a well organised outpatient clinic using directly observed treatment. These results are similar to results obtained in countries using this measure of control. ${ }^{14} 16173640-45$ The detection rate of smear positive cases is estimated to be over $70 \%$ because of the good distribution of health centres and physicians and nurses throughout the country.

It seems that in Cuba the influence of the HIV epidemic, ${ }^{47}$ migratory phenomena, ${ }^{48}$ and multiresistant tuberculosis ${ }^{46} 49$ have been minor. The lack of efficacy in the national tuberculosis programme, especially due to economic difficulties and the fact that tuberculosis was an infrequent disease in a health system with almost 30000 physicians in the primary health care setting, may have contributed to a reduced case finding and thus to a resurgence of the disease. The average annual decrease was $5 \%$ from 1965 to 1991 , a little less than in the period 1995-7 (6.4\%). Better case finding and the change in the case definition may explain the increase in the period 1992-4. However, the decrease obtained from 1996 to 1997
$(9.6 \%)$ was certainly influenced by a reduction in the diagnostic delay and the different interventions in the study of contacts.

There was an important decrease in the detection rate of patients with respiratory symptoms for more than 14 days between 1989 and 1992 as well as a lower number of bacteriological studies carried out in this group, which most probably resulted in an underdetection of cases, a problem present in almost all countries with low economic resources. ${ }^{16}$ In 1993, when emphasis was placed on the correction of this measure (improved information, education and supervision), there was a subsequent clear increase in the identification of patients with respiratory symptoms lasting for more than 14 days and in the number of smear tests performed. This resulted in an increased detection of patients, which was even higher in 1994 when the case definition was changed to include clinicoradiological cases. Although the delay in the detection of cases is a poorly studied indicator in most national tuberculosis programmes, ${ }^{9} 1736{ }^{43-45}$ this parameter is of crucial importance in countries with a low prevalence of tuberculosis infection, especially the delays attributable to the health care system (from initial consultation to treatment). This delay was nearly two months in Cuba in 1993 and it is likely that this led to an increase in the number of infected persons in the community. This delay has been reduced considerably in recent years (14.2 days in 1997). Strengthening the programme, especially by improving information and education for the general population and the health care personnel as well as increased supervision, led to reduced intervals in the diagnostic delay (table 4).

Economic difficulties after the fall of the socialist bloc, ${ }^{26} 37{ }^{38}$ in addition to logistical obstacles in the implementation of the national tuberculosis programme, led to a deterioration in the nutritional status and to an increase in cases of tuberculosis resulting from endogenous reactivation among subjects previously infected. ${ }^{38}$ Although rates of new cases of tuberculosis were similar to those achieved in industrialised countries, ${ }^{7-10} 121735364344$ it was not possible to engage more aggressively in the study of contacts of patients over 15 years of age. ${ }^{48}$ It is well known that annual decreases of $12-14 \%$ can be attained ${ }^{13} 42$ if high cure ratios and high detection rates are achieved. This percentage might be further increased if examination of contacts is systematically pursued and directly observed preventive therapy is provided to those eligible for it. ${ }^{17}{ }^{44}$ This may be a fundamental measure when most patients are adults, as in the case of Cuba. By concentrating particularly on factors identified as having caused the increase in the period 1992-4 such as intensifying contact tracing and examination of contacts, Cuba could therefore try to achieve an annual decrease of $10 \%$ (as obtained in 1997). The systematic study of contacts and of high risk groups ${ }^{48} 50$ with the subsequent administration of directly observed chemoprophylaxis has already been adopted in the national tuberculosis pro- 
gramme in 1997 as one of the priority measures. These are measures relatively easy applied in Cuba, given the characteristics of the health system and the adequate distribution of primary health care centres and laboratories (one centre with a physician and nurse for each $300-500$ persons). ${ }^{49}$ For this reason a $10 \%$ annual decrease seems to be an achievable objective resulting in elimination of tuberculosis by the year 2016 (incidence rate of 0.93 per 100 000), provided the AIDS epidemic does not interfere with the epidemiology of tuberculosis in the future. ${ }^{47}$ However, the distribution of tuberculosis cases by age (fig 2), which is similar to that found in industrialised nations, ${ }^{2} 1012$ would indicate that, even if there were a substantial increase in the AIDS epidemic in Cuba, this would not significantly affect the epidemiological trends of tuberculosis. ${ }^{2}$

The high cost of planning and implementing a national tuberculosis programme has been one of the arguments consistently used to justify the tuberculosis pattern worldwide. ${ }^{19}$ However, if a greater priority was given to combatting tuberculosis with internal resources and, if necessary, with external aid, better results could be obtained. ${ }^{65}$ The national tuberculosis programme and the public health care system of Cuba were considered to be very expensive and, for this reason, a nonexportable model to other developing countries, ${ }^{51}$ partly because it was also taking advantage of the economic aid of the former Soviet Union. ${ }^{26}$ However, it should be noted that Cuba always spent an important proportion of its gross national product on health care (similar to that of industrialised countries $^{26}$ ), a fact that led to the development of a health system that has been able to remain firm and to obtain positive results (occasionally with difficulties), even after the disappearance of the socialist bloc, and this with very limited external aid. Cuba has always fulfilled all elements considered essential by the World Health Organisation ${ }^{24}$ and the International Union Against Tuberculosis and Lung Disease (IUATLD) $)^{52}$ for tuberculosis control. The support and political commitment of the government for the national tuberculosis programme and its integration into the primary health care system (no specialised tuberculosis control system) and the excellent distribution of health care centres represent a good example of how, by fulfilling control strategies advocated by the World Health Organisation and IUATLD, elimination of tuberculosis can become a realistic goal, even in countries with low economic resources.

1 Sauret J. La tuberculosis a traves de la historia. Madrid: Editorial Rayma, 1990

2 Murray JF. An emergency global programme against tuberculosis: agenda for research, including the impact of HIV infection. Bull Int Tuberc Lung Dis 1991;66:207-9.

3 Narain JP, Raviglione MC, Kochi A. HIV-associated tuberculosis in the developing countries: epidemiology and strateges for prevention. Tuberc Lung Dis 1992;73:311-21.

4 De Cock KM, Soro B, Coulibaly MI, et al. Tuberculosis and HIV infection in sub-Saharan Africa. $\mathcal{F} A M A$ 1992;268: 1581-7.

5 Yanai $\mathrm{H}$, Uthaivoravit W, Pnich V, et al. Rapid increase in HIV-related tuberculosis, Chiang Rai, Thailand, 19901994. AIDS 1996;10:527-31.

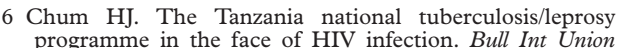
programme in the face of HIV infection
Tuberc Lung Dis 1991;66 (Suppl):53-5.

7 Raviglione MC, Snider DE Jr, Kochi A. A global epidemiology of tuberculosis: morbidity and mortality of a worldwide epidemic. $\mathcal{F} A M A$ 1995;273:220-6.

8 Raviglione MC, Rieder HL, Styblo K, et al. Tuberculosis trends in Eastern Europe and former USSR. Tuberc Lung Dis 1994;75:400-16.

9 Cantwell MF, Snider DE Jr, Cauthen GM, et al. Epidemiology of tuberculosis in the United States, 1985 through 1992. FAMA 1994;272:535-9.

10 Clancy L, Rieder HL, Enarson DA, et al. Tuberculosis elimination in the countries of Europe and other industrialized countries. Eur Respir f 1991;4:1288-95.

11 McKenna MT, McCray E, Onorato I. The epidemiology of tuberculosis among foreign-born persons in the United States, 1986 to 1993 . N Engl f Med 1995;332:1071-6.

12 Raviglione MC, Sudre P, Rieder HL, et al. Secular trends of tuberculosis in Western Europe. Bull World Health Org tuberculosis in West

13 World Health Organisation. WHO Expert Committee on tuberculosis. Ninth report. Geneva: World Health Organisation, 1974

14 Styblo K. Epidemiology of tuberculosis. In: Infektionskrankheiten und ihre Erreger. Volume 4/IV. Jena, Germany: VEB Gustav Fischer Verlag, 1984

15 Grzybowski S, Styblo K, Dorken E. Tuberculosis in Eskimos. Tubercle 1976;57(Suppl 1):58.

16 Raviglione MC, Dye D, Schmidt S, et al. Assessment of worldwide tuberculosis control. WHO global surveillance and monitoring project. Lancet 1997;350:624-9.

17 Frieden TR, Fujiwara PI, Washko RM, et al. Tuberculosis in New York city. Turning the tide. $N$ Engl $\mathcal{f}$ Med 1995;333:229-33.

18 Rieder HL. Misbehaviour of a dying epidemic: a call for less speculation and better surveillance. Tubercle 1992;73:181-3.

19 Yankauer A. What do you want from WHO? Am f Public Health 1980;70:681-2.

20 Farga V. Programas de control de la tuberculosis. In: Farga V, ed. Tuberculosis. 2nd ed. Santiago de Chile: Publicaciones Técnicas Mediterrantas Ltda, 1992: 249-63.

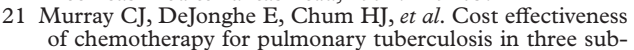
Saharan African countries. Lancet 1991;338:1305-8.

22 Styblo K. The impact of HIV infection on the global epidemiology of tuberculosis. Bull Int Union Tuberc Lung Dis 1991; 66:27-32

23 Rieder HL. Tuberculosis and HIV interventions. Tuberc Lung Dis 1995;76(Suppl 2):6.

24 World Health Organisation. WHO tuberculosis programme: framework for effective tuberculosis control. WHO/TB/94.179. framework for effective tuberculosis control. W

25 Canetti G, Rist N, Grosset J. Mesure de la sensibilité du bacille tuberculeux aux drogues antibacilaires par la methode des proportions. Rev Tuberc Pneumol 1963;27:263-72.

26 Pérez-Stable EJ, Pedraza RO. Tuberculosis in Cuba. Am Rev Respir Dis 1984;130:520-3.

7 Aldereguía G. Nuestra experiencia en programmea de control de tuberculosis sobre la base de la pesquisa bacteriológica y tratamiento ambulatorio controlado. $\mathrm{Bo}$ letín Higiene y Epidemiología 1972;10:41-52.

28 González E, Caraballoso M. Massive application of a antituberculosis chemoterapeutique programme in Cuba. Bull Int Union Tuberc 1974;49:118-26.

29 González E, García MM, Armas L. Stages of the historic evolution of the antituberculosis campaign in Cuba. Rev Cubana Med Trop 1993;45:49-54.

30 González E, Armas L, Alonso A. Tuberculosis in the Republic of Cuba: its possible elimination. Tuberc Lung Dis Republic of Cub.

31 Department of Health and Human Services, Centers for Disease Control. 1980 tuberculosis statistics, states, and cities. Publication no. (CDC) 82-8249. Washington: US Government Printing Office, 1982

32 Bienia RA, VanDerDecker JD, Bienia BH. Cuban refugee health care: response of the American health care system to the unexpected arrival of 125,000 immigrants. Am f Public Health 1982;72:594-6.

33 Anonymous. Prevalence of tuberculosis infection among US Cuban descent, Dade Country, Florida, 1982-84. MMWR 1992;41:74-5, 81.

34 De Kantor IN, Ritacco V. Bovine tuberculosis in Latin America and the Caribbean: current status, control and America and the Caribbean: current status, contro

35 Collaborative Group for the Study of Tuberculosis in Spain. Tuberculosis and Respiratory Infection Working Group (Spanish Society of Pneumology and Thoracic Surgery). Epidemiological trends of tuberculosis in Spain from 1988 to 1992. Tuberc Lung Dis 1995;76:522-8.

36 Centers for Disease Control and Prevention. Reported tuberculosis in the United States, 1994. Washington: US Department of Health and Human Services, 1995.

37 González E, Armas L, Machin A. The trends by province of tuberculosis in Cuba: 1979-1993. Bol Oficina Sanit Panam 1995;119:369-404.

38 Marrero A, Carreras L. El programa de control de la tuberculosis en Cuba. Rev Cubana Med Gen Integr 1996;12:381-

39 World Health Organisation. Forty-fourth World Health Assembly, Geneva, 6-16 May 1991. WHA44/1991/REC/1. Assembly, Geneva, 6-16 May 1991.

40 Farer LS. The current status of tuberculosis control efforts. Am Rev Respir Dis 1986;134:402-7. 
41 Sutherland I. Epidemiology of tuberculosis: is preventing better than treating? Bull Int Union Tuberc 1981;56:139-46.

42 Perdrizet S, Styblo K, Rouillon A. Evaluación del impacto epidemiológico de la quimioterapia. Bol Un Int Tuberc 1985;60:24.

43 Bureau of Tuberculosis Control, New York City Department of Health. Tuberculosis in New York City. Information summary. 1994.

44 Bureau of Tuberculosis Control, New York City Department of Health. Tuberculosis in New York City. Information summary. 1995

45 Heldal E, Cruz JR, Arnadottir T, et al. Successful management of a national tuberculosis programme under conditions of war. Int $\mathcal{F}$ Tuberc Lung Dis 1997;1:16-24.

46 World Health Organisation. Anti-tuberculosis drug resistance in the world. WHO/TB/97.229. Geneva: World Health Organisation, 1997.

47 Torres R, Marrero A, Carreras L. La infección por el virus de la immunodeficiencia humana y la tuberculosis en Cuba. Bol Of Sanit Panam 1995;19:66-8.
48 Centers for Disease Control, US Department of Health and Human Services. Essential components of a tuberculosis prevention and control programme. Screening for tuberculosis and tuberculosis infection in high-risk populations. Recommendations of Advisory Council for the Elimination of Tuberculosis. MMWR 1995;44:1-34.

49 Valdivia JA, Jiménez CA, Ferrá C, et al. The laboratorio nacional de referencia de mycobacteria y tuberculosis in the antituberculosis campaign in Cuba. Rev Cubana Med Trop 1988;40:51-66.

50 Rieder HL, Cauthen GM, Comstock GW, et al. Epidemiology of tuberculosis in the United States. Epidemiol Rev
inted 1989;11:79-98.

51 Grundy PH, Budetti P. The distribution and supply of Cuban medical personnel in the third world countries. Am f Public Health 1980;70:717-9.

52 Enarson DA. Principles of IUATLD collaborative tuberculosis programmes. Bull Int Union Tuberc Lung Dis 1991;66: 195-200. 